\title{
DESDOBRAMENTOS SOCIOCULTURAIS DA MIGRAÇÃO E MISCIGENAÇÃO
}

Karina Bornia Pedroso Gomes; Célia dos Santos Silva; Fábio Ferreira Morong

Universidade do Oeste Paulista - UNOESTE, Especialização em Perícia Forense, Presidente Prudente, SP. karinabbio@gmail.com; celiasilva@unoeste.br; fabiomorong@hotmail.com

\begin{abstract}
RESUMO
É sabido que o mundo chegou à configuração atual de pessoas, países e culturas através de séculos de migrações e subsequente miscigenação. Em quase todos os continentes, o que se entende por "cultura" é fruto da contribuição dos diversos povos que ali se estabeleceram, seja em decorrência de fluxos migratórios voluntários, colonização imperialista ou regimes escravocratas. No entanto, o que deveria ser considerado algo positivo e enriquecedor, dá base para todo tipo de preconceito e exclusão. Através de pesquisas científicas e análise crítica dos fatos, o presente artigo visa analisar os porquês dessas violências e o que está sendo feito e ainda se pode fazer para combatê-las. Tais análises permitiram inferir que, a despeito da existência de mecanismos legais para coibir o preconceito, a intolerância e a discriminação, ainda convivemos com eles, sendo necessária uma intervenção mais incisiva do Estado no campo das ideias e da educação, que devem ser voltadas para o respeito ao próximo e aos direitos humanos.
\end{abstract}

Palavras-chave; Miscigenação; preconceito; direitos humanos; legislação; educação.

\section{SOCIAL AND CULTURAL CONSEQUENCES OF MIGRATION AND MISCEGNATION}

\begin{abstract}
It is known that the world has reached the present configuration of people, countries, cultures, through centuries of migrations and subsequent miscegenation. On almost all continents, what is meant by "culture" comes from the contribution of various peoples who have settled there, whether due to voluntary migratory flows, imperialist colonization or slave regimes. However, what should be considered positive and enriching, provides a basis for all kinds of prejudice and exclusion. Through scientific research and critical analysis of the facts, this article aims to analyze the reasons for these violence and what is being done and can still be done to combat them. These analyzes allowed us to infer that, despite the existence of legal mechanisms to curb prejudice, intolerance and discrimination, we still live with them, requiring a more incisive intervention of the State in the field of ideas and education, which must be addressed to respect for others and human rights.
\end{abstract}

Keywords: Miscegenation; prejudice; human rights; legislation; education. 


\section{INTRODUÇÃO}

O Brasil é um país essencialmente miscigenado. Ao longo da história, recebeu pessoas de todas as partes do mundo e isso gerou toda essa pluralidade vista aqui. Tal diversidade gera uma incomparável oferta cultural e social, consequência da vastidão de crenças, origens e etnias presentes no território brasileiro. Além dessas, há as "diferenças naturais" entre os seres humanos de uma mesma população, tais como gênero, cor da pele, deficiências, idade e linguagem. Embora seja saudável essa convivência com o que é diferente, pessoas com determinadas características, tão comuns no cotidiano, estão mais suscetíveis a terem seus direitos desrespeitados.

Um exemplo cotidiano deste desrespeito é o que acontece com os descendentes de povos escravizados - que foram prejudicados pelo Estado para se reintegrarem à sociedade pós abolição, sendo excluídos do mercado de trabalho e de oportunidades de moradia - e atualmente ainda se encontram em situação de vulnerabilidade. Esse contexto forja uma situação de insegurança social, e ainda que nossa Constituição e tantos outros dispositivos legais assegurem a igualdade e a equidade entre todas as pessoas - e o Brasil tem legislações muito completas sobre Direitos Humanos, reconhecidas internacionalmente como avançadas, a teoria não corresponde à realidade. Neste artigo, serão analisados os conceitos de "minoria", "grupo vulnerável", as origens do preconceito, intolerância e discriminação e os aparatos legais e ideológicos disponíveis para resolução dessas mazelas, especialmente as relacionadas à questão migratória.

\section{METODOLOGIA}

O presente trabalho utilizou-se de pesquisas científicas sobre os temas abordados e informações sobre a legislação vigente sobre o problema. O método utilizado para sintetizar os dados e realizar as análises foi o dedutivo.

\section{RESULTADOS}

O Brasil sempre foi conhecido por ser hospitaleiro e receptivo às diferenças. Entretanto, é notável uma onda crescente de intolerância - não só aqui, como em todo o mundo. Com episódios recorrentes na história da humanidade, esse fenômeno é retroalimentado pelo discurso de normatização social, que separa as pessoas em categorias e segrega o que é diferente.

Tal normatização é ilustrada na distopia Admirável Mundo Novo, de Aldous Huxley, publicado pela primeira vez em 1932, onde as pessoas vivem sob forte controle social estatal com o objetivo de condicionar a todos desde o nascimento para serem o que a sociedade espera de cada um, vivendo, assim, em paz.

Um dos estopins para o renascimento do fantasma da intolerância certamente foi a internet, pois ela deu voz - uma voz anônima, segura, sem rosto e sem responsabilidade - aos intolerantes e os organizou em grupos (JESUS, 2003). Outro estopim primordial relacionado ao ressurgimento do preconceito patológico como fenômeno social é a recente onda de migração que tem ocorrido ao redor do globo.

Desde os primórdios da civilização, as colônias humanas migraram em busca de comida, água e melhores condições de sobrevivência, e a migração nunca deixou de existir (MARTINE, 2005). Porém, no mundo moderno, ela passou a ter um caráter político e social, sendo consequência, principalmente, de conflitos armados, questões econômicas e ambientais, a exemplo da grande diáspora causada na Europa em consequência da fome e a destruição que 
assolaram esse continente após a Primeira Grande Guerra, e que trouxe muitos imigrantes para o Brasil no início do século XX. Ou seja, como exposto por Martine (2005), os padrões migratórios são influenciados por mudanças econômicas e sociais.

Ainda hoje, por esse mesmo motivo, grandes contingentes humanos saem de suas pátrias todos os dias, em busca de segurança e oportunidades. O Brasil é atualmente um destino eletivo para muitos migrantes, oriundos em especial do Oriente Médio, América Latina e América Central. Segundo o Comitê Nacional para Refugiados (CONARE), vinculado ao Ministério da Justiça, o Brasil tinha, em 2017, 10.141 refugiados e mais de 30 mil solicitações de refúgio a serem analisadas.

A chegada desses migrantes tem desagradado muitos nativos, o que provoca uma série de problemas locais, mas que reverberam em caráter global. Essa situação desencadeia uma série de preconceitos, que levam ao renascimento de movimentos neonazistas, inclusive em nosso país (DE ANDRADE, 2014), com a diferença que o nazismo atual se caracteriza pelo repúdio cultural, e não apenas racial (JESUS, 2003), o que explica os atuais movimentos xenófobos, separatistas e ultranacionalistas vistos em todo o mundo.

Como observado, a questão da dinâmica das populações mundiais, que parece tão distante, traz à tona questões cotidianas como racismo, intolerância religiosa e tantos outros tipos de discriminação; questões essas que por muito tempo foram consideradas sepultadas em nossa sociedade, gerando uma falsa sensação de paz social, mas que estavam apenas em estado de hibernação, esperando o momento certo de despertar.

Mesmo com a proclamação da Declaração Universal dos Direitos Humanos em 1948 (ONU, 1948) que teoricamente veio para igualar e proteger a todos - aqueles que constituem os vulneráveis em nossa sociedade (mulheres, idosos, pessoas com deficiência, pessoas em situação de rua, crianças e a população LGBTQI+) e as minorias étnicas, religiosas e linguísticas, exemplificadas aqui pelos migrantes, continuaram tendo seus direitos desrespeitados.

Assim, outros documentos se fizeram necessários para assegurar proteção adicional a esses grupos. A Declaração Sobre os Direitos das Pessoas Pertencentes a Minorias Nacionais, Étnicas, Religiosas e Linguísticas (ONU, 1992), estabelece em seu artigo primeiro que cabe ao Estado a proteção da existência e da identidade das minorias, adotando medidas que visem alcançar esse objetivo, além de várias outras orientações para que cada minoria tenha sua dignidade preservada.

Além deste documento, o Pacto Internacional dos Direitos Civis e Políticos (BRASIL, 1992), vigente no Brasil desde 6 de julho de 1992, diz em seu artigo 27 que:

Nos Estados em que existam minorias étnicas, religiosas ou linguísticas, não será negado o direito que assiste às pessoas que pertençam a essas minorias, em conjunto com os restantes membros do seu grupo, a ter a sua própria vida cultural, a professar e praticar a sua própria religião e a utilizar a sua própria língua.

Ou seja, tais dispositivos garantem e protegem o pleno exercício das particularidades de cada cultura, ainda que em território diverso daquele de origem.

Recentemente, a nova lei de migração, Lei 13.445 de 24 de Maio de 2017 (BRASIL, 2017), foi instituída para encontrar soluções para a questão migratória, dispondo sobre os direitos e deveres do migrante, regulando sua entrada no país e a promoção de políticas públicas voltadas para esta minoria. Porém, é importante notar que já existiam no Brasil outras legislações com o mesmo objetivo, a exemplo da Lei 9.474 de 22 de Julho de 1997 (BRASIL, 1997), que adotou um conceito amplo de refugiado e criou o Comitê Nacional para Refugiados, cuja função é receber as solicitações de abrigo e assistir os migrantes em suas demandas; e que o Brasil é parte da 
Convenção Relativa ao Estatuto dos Refugiados, de 1951 (ONU,1951) e também subscreve o Protocolo sobre o Estatuto dos Refugiados, de Janeiro de 1967 (ONU, 1967).

Para entender melhor porque tais documentos são importantes, é preciso entender o que são minorias. Segundo Francesco Capotorti (1979), minorias são:

Um grupo numericamente inferior ao resto da população de um Estado, em posição não dominante, cujos membros - sendo nacionais desse Estado - possuem características étnicas, religiosas ou linguísticas diferentes das do resto da população e demonstre, pelo menos de maneira implícita, um sentido de solidariedade, dirigido à preservação de sua cultura, de suas tradições, religião ou língua.

Portanto, não há um consenso internacional nem um conceito universal sobre quem são as minorias, devido à sua forte correlação com o aspecto histórico e às muitas variáveis socioculturais envolvendo cada minoria. Assim, cabe a cada Estado identificar e classificar as minorias presentes em seu território, com base em critérios objetivos, como a existência de uma etnia, linguagem e religião em comum, e subjetivos como a identificação de seus membros como pertencentes a uma minoria (ONU, 2010).

Também é interessante notar que a palavra "minoria" não se limita a descrever a quantidade, e sim a hegemonia - ou falta dela - de determinados grupos na sociedade em que tal minoria está inserida. Sendo assim, sua posição é um produto das relações de poder. Ou seja, esse grupo minoritário pode estar em vantagem numérica perante o resto da sociedade, mas ainda assim estar em uma posição de submissão, a exemplo dos negros sob o regime do Apartheid, na África do Sul (MENDES CHAVES,19--). Quanto aos grupos vulneráveis, não se observa uma conexão cultural como a existente nas minorias, mas sim uma conexão advinda da condição de vulnerabilidade social trazida por elementos como gênero, idade, orientação sexual, deficiência e condição social (SIQUEIRA; CASTRO, 2017). Porém, pode existir intersecção desses dois grupos e uma pessoa fazer parte de uma minoria e de um grupo vulnerável ao mesmo tempo.

É bem verdade que a discriminação é um comportamento recorrente nas sociedades organizadas, mas o que se observa atualmente é um ataque forte, deliberado e organizado às pessoas "fora do padrão". Tais ataques são admitidos e legitimados sob a forma de "liberdade de expressão" ou "opinião". Porém, com apenas uma breve observação da realidade através da história, é fácil perceber onde essa intolerância pode chegar.

\section{DISCUSSÃO}

É evidente que o Brasil vive um momento de insegurança (política, econômica, e social) que exacerba lapsos de preconceito, discriminação e intolerância. Portanto, este é um momento de necessidade de extremo cuidado do Estado - aquele com a prerrogativa da aplicação da Justiça -, de coibir os atos de intolerância.

A proclamação da Declaração Universal dos Direitos Humanos foi um marco na história, pois pela primeira vez reconheceu-se que todos são iguais, independente de sua etnia, religião, sexo e orientação sexual. Ainda assim, tal documento não foi suficiente para promoção da igualdade, sendo necessária a criação de outros dispositivos legais para proibir a irradiação de movimentos discriminatórios e proteger as minorias e os grupos vulneráveis.

Essa constatação traz a seguinte dúvida: como prevenir, combater e coibir, de maneira efetiva, ideias segregadoras e intolerantes, já que mesmo com tantos códigos regulamentadores, ainda somos uma sociedade preconceituosa? 


\section{CONCLUSÃO}

Está claro que a área de combate à intolerância é o pensamento, pois o preconceito reside no mundo das ideias. Porém, a discriminação não é tão simples de tratar como a intolerância. Enquanto a segunda se apresenta em rompantes violentos um tanto raros, a primeira é lugar-comum. Nem está toda ela à face da lei, porque está sempre camuflada na mente humana.

Portanto, o principal meio de combater a discriminação, a intolerância e o preconceito, é uma educação voltada para o respeito às diferenças e aos direitos humanos, e esse é o papel do Estado: criar meios de combater tais ideias, tanto de maneira ostensiva, através de leis e sanções, programas de acolhimento e secretarias especializadas, quanto de maneira subjetiva, fomentando nos indivíduos a fraternidade humana. Porém, cada cidadão também têm sua parcela de responsabilidade, porque se a internet uniu aqueles que segregam pessoas, também deu poderes a todos que lutam pela igualdade e dignidade do ser humano.

\section{REFERÊNCIAS}

BRASIL. PLANALTO. Constituição da República Federativa do Brasil. Brasília: Senado Federal, 1988. Disponível em <http://www.planalto.gov.br/ccivil_03/constituicao/constituicao.htm>. Acesso em: 04 ago. 2018.

BRASIL. PLANALTO. Pacto Internacional Sobre os Direitos Civis e Políticos. Disponível em <http://www.planalto.gov.br/ccivil_03/decreto/1990-1994/d0592.htm>. Acesso em: 04 ago. 2018.

BRASIL. PLANALTO. Estatuto do Refugiado. Disponível em <http://www.planalto.gov.br/ccivil_03/leis/I9474.htm>. Acesso em: 16 set. 2018.

BRASIL. PLANALTO. Lei de Migração. Disponível em <http://www.planalto.gov.br/ccivil_03/_Ato2015-2018/2017/Lei/L13445.htm>. Acesso em: 16 set. 2018.

CARMO, C. M. Grupos minoritários, grupos vulneráveis e o problema da (in)tolerância: uma relação linguístico-discursiva e ideológica entre o desrespeito e a manifestação do ódio no contexto brasileiro. Revista do Instituto de Estudos Brasileiros. N 64. Ago 2016. P 201-233. Disponível em <http://dx.doi.org/10.11606/issn.2316-901X.v0i64p201-223>. Acesso em: 04 ago. 2018.

CAPOTORTI, Francesco 1979. Study on the Rights of Persons Belonging to Ethnic, Religious and Linguistic Minorities; 1979. United Nations Office of the High Commissioner for Human Rights (UNOHCHR). 1998. Rev.1, Minority Rights.

DE ANDRADE, G. I. F. O Nacional-Socialismo do grupo Valhalla 88: a construção de um movimento nazista no Brasil. Dossiê - Pensamento de Direita e Chauvinismo na América Latina. Mediações, Londrina, V. 19 N. 1, P. 18-40, Jan./Jun. 2014. Disponível em 10.5433/21766665.2014v19n1p18. Acesso em: 04 ago. 2018.

HUXLEY, ALDOUS. Admirável Mundo Novo. 21 edição. Editora Globo, 2012. 
JESUS, C. G. N. Neonazismo: nova roupagem para um velho problema. AKRÓPOLIS - Revista de Ciências Humanas da UNIPAR, v.11, n.2, abr./jun., 2003

MARTINE, G. A globalização inacabada: migrações internacionais e pobreza no século 21. São Paulo em Perspectiva. 19, n. 3, p. 3-22, jul./set. 2005. https://doi.org/10.1590/S0102$\underline{88392005000300001}$

MENDES CHAVES, L. G. Minorias e seu estudo no Brasil. Revista de Ciências Sociais, Vol II N 1.

ORGANIZAÇÃO DAS NAÇÕES UNIDAS. Protegendo Refugiados no Brasil e no Mundo. Disponível em <http://www.acnur.org/portugues/wp-content/uploads/2018/02/Protegendo-Refugiadosno-Brasil-e-no-Mundo_ACNUR-2018.pdf>. Acesso em: 16 set. 2018.

ORGANIZAÇÃO DAS NAÇÕES UNIDAS. Convenção Relativa ao Estatuto dos Refugiados. 28 jul $1951 . \quad$ Disponível em <http://www.acnur.org/fileadmin/Documentos/portugues/BDL/Convencao_relativa_ao_Estatut o_dos_Refugiados.pdf?view=1>. Acesso em: 16 set. 2018.

ORGANIZAÇÃO DAS NAÇÕES UNIDAS. Protocolo Sobre o Estatuto dos Refugiados. 31 jan 1967. Disponível em <http://www.acnur.org/fileadmin/Documentos/BDL/2001/0003.pdf?file=t3/fileadmin/Docume ntos/BDL/2001/0003>. Acesso em: 16 set. 2018.

ORGANIZAÇÃO DAS NAÇÕES UNIDAS. Relatório alerta para o aumento de casos de intolerância religiosa no Brasil. 10 mar 2017. Disponível em <https://nacoesunidas.org/relatorio-alerta-paraaumento-dos-casos-de-intolerancia-religiosa-no-brasil/>. Acesso em: 04 ago. 2018.

ORGANIZAÇÃO DAS NAÇÕES UNIDAS. Promoting and Protecting Human Rights: A Guide for Advocates. Geneva and New York. 2012. 185 p. Disponível em: < https://www.ohchr.org/Documents/Publications/HR-PUB-12-07_en.pdf>. Acesso em 04 ago. 2018.

ORGANIZAÇÃO DAS NAÇÕES UNIDAS. Minority Rights: International Standards and Guidance for Implementation. Geneva and New York. 2010. 48 p. Disponível em: < https://www.ohchr.org/Documents/Publications/MinorityRights_en.pdf >. Acesso em 04 ago. 2018.

SIQUEIRA, D. P.; Castro, L. R.B. Minorias e Grupos Vulneráveis: a questão terminológica para como fator preponderante para uma real inclusão social. Revista Direitos Sociais e Políticas Públicas (UNIFAFIBE), VOL. 5 , N. 1 , 2017. Disponível em <http://dx.doi.org/10.25245/rdspp.v5i1.219>. Acesso em 04 ago. 2018.

USP - Universidade de São Paulo. Resolução 47/135. Declaração sobre os Direitos das Pessoas Pertencentes a Minorias Nacionais, Étnicas, Religiosas e Linguísticas. Assembleia Geral da Organização das Nações Unidas, 1992. Disponível em: <http://www.direitoshumanos.usp.br/index.php/Preven\%C3\%A7\%C3\%A3o-contra-aDiscrimina\%C3\%A7\%C3\%A3o-e-Prote\%C3\%A7\%C3\%A3o-das-Minorias/declaracao-sobre-os- 
direitos-das-pessoas-pertencentes-a-minorias-nacionais-ou-etnicas-religiosas-elinguisticas.html.> Acesso em 04 ago. 2018. 